\begin{tabular}{|c|c|}
\hline \multirow{3}{*}{ 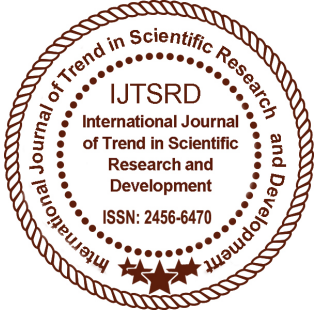 } & $\begin{array}{l}\text { International Journal of Trend in Scientific } \\
\text { Research and Development (IJTSRD) }\end{array}$ \\
\hline & International Open Access Journal \\
\hline & ISSN No: 2456 - 6470 | www.ijtsrd.com | Volume - 2 | Issue - 5 \\
\hline
\end{tabular}

\title{
Study the Effect of Using Subordinate Grass Ash on Mechanical Properties in Fabrication of Ceramics
}

\author{
Mr. M. Siva Manojkumar ${ }^{1}$, Mr. D. Harshavardhan ${ }^{2}$, Mr. K. Viswanath ${ }^{3}$ \\ ${ }^{1}$ Research Scholar, ${ }^{2}$ Head of Department, ${ }^{3}$ Assistant Professor \\ Department of Mechanical Engineering Research, Sri Venkateswara Institute of Technology, \\ Anantapuramu, Andhra Pradesh, India
}

\begin{abstract}
Ceramics have been used since the earliest civilization. The field of ceramic materials has its roots in more traditional aspects of the subject like clay based ceramics and glasses. Ceramics are defined as solid compounds that are formed by the application of heat and sometimes heat and pressure. It has been defined ceramics as, "the art and science of making and using solid articles, which have as their essential component, and are composed in large part of, inorganic nonmetallic materials. Sub-ordinate grass ash is consider for manufacture of ceramics since it has rich silica content and easily available in cheaper cost. Ceramics are developed by using polyvinyl alcohol as binder in composition of silica, the composition is heated at temperature of $1000 \mathrm{deg}-\mathrm{c}$ at 3hours, the samples are prepared by varying composition of silica. The newly developed ceramics samples are exhibit better mechanical characteristics like compressive, flexural strengths.
\end{abstract}

KEYWORD: Subordinate grass ash, polyvinyl alcohol, compressive and flexural strength

\section{INTRODUCTION}

Composites are made by the combination of two or more dissimilar materialsim order to achieve properties that the constituent materials cannot provide by themselves individually. In fact, the development of composite is based on the idea of combining materials to utilize jointly the best characteristics of each. The dimensions of one of the constituents of a composite material are smaller than those of the second, where first being known as reinforcement and the other as matrix.
Certain properties of a composite depend only on the relative amounts and properties of the individual constituents. The rule of mixtures can accurately predict these properties.

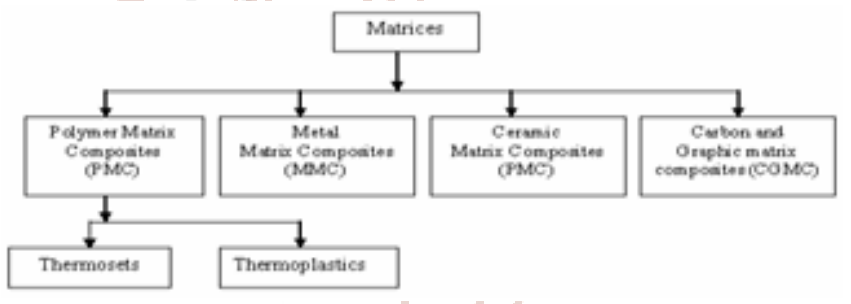

Figure1 Types of composites based on matrices

The second level of classification refers to the reinforcement form - fibre reinforced composites, laminar composites and particulate composites.

Fibre Reinforced composites (FRP) can be further divided into those containing discontinuous or continuous fibres. Fibre Reinforced Composites are composed of fibres embedded in matrix material. Such a composite is considered to be a discontinuous fibre or short fibre composite if its properties vary with fibre length.

Laminar Composites are composed of layers of materials held together by matrix. Sandwich structures fall under this category.

$>$ Particulate Composites are composed of particles distributed or embedded in a matrix body. The particles may be flakes or in powder form. Concrete and wood particle boards are examples of this category.

Thermoplastics have one- or two-dimensional molecular structure and they tend to at an elevated temperature and show exaggerated melting point. 
Another advantage is that the process of softening at elevated temperatures can reversed to regain its properties during cooling, facilitating applications of conventional compress techniques to mould the compounds.

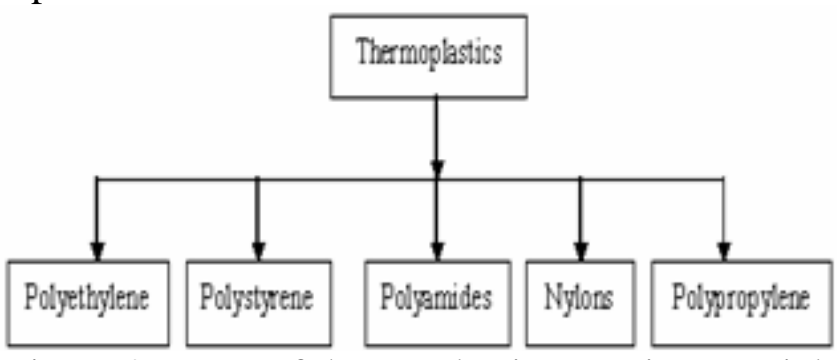

Figure 2 Types of thermoplastics matrix material

Thermo sets are the most popular of the fiber composite matrices without which, research and development in structural engineering field could get truncated. Aerospace components, automobile parts, defense systems etc., use a great deal of this type of fiber composites. Epoxy matrix materials are used in printed circuit boards and similar areas.

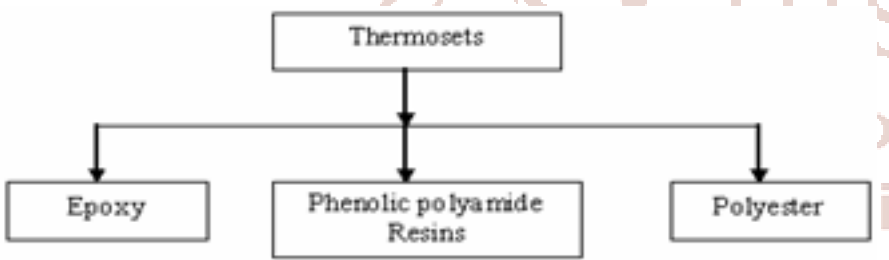

Figure 3 Types of thermo sets matrix material

Carbon-carbon composites can retain its mechanical properties at high temperatures in inert atmosphere only as like any carbon material they have poor oxidation resistance. The oxidation problem in carbon-carbon composites can be overcome either by coating the composites with oxidation resistant ceramic materials or by making ceramic matrix composites with high oxidation resistance.

Silica is the most commonly available ceramic material and can be used as such or in combination with other elements and compounds as matrix system for high temperature composites. Silica and Silicon based ceramics possess desirable thermal properties for use as matrix materials for ceramic matrix composites. Moreover, these are simpler to process as compared to other ceramics. Therefore, as per literature survey comparatively large efforts have been concentrated to develop silica and silicon based ceramic matrix composites.

The raw materials for making traditional ceramics are not costly. However, high tech ceramic require highly pure raw materials. The processing temperature for hi- tech ceramics are also higher. Therefore the two factors add together to make hitech ceramics cost prohibitive materials. High cost of reinforcing materials add to the cost of fiber reinforced ceramic materials and production routes coupled with low demand patterns have restricted the applications of high tech ceramics and ceramic composites to only narrow areas such as aerospace, nuclear and hi-tec programmes. More emphasis has been on aerospace programs, where increased materials capabilities and decreased weight can result in tremendous increase in performance and hence can pay back the cost. For such applications, the brittle failure mode of monolithic ceramics or even whisker reinforced ceramic can ordinarily not be tolerated. The major developmental efforts have involved CVI produced silicon carbide matrix composites for a variety of components for aerospace vehicles, which include nose cones, leading edges, fins and rudders.

Sub-ordinate grass is namely called as sopa in telugu. This grass is also rich in silicon content and it can be used as content in fabrication of ceramics.

\section{MATERIALS AND METHODS \\ Materials:}

The materials that are used in the fabrication of ceramics are silicon, soda ash, dolomite, aluminium oxide, polyvinyl alcohol (Binder), subordinate grass ash.

\section{FORMATION OF SUBORDINATE GRASS:}

Silica ash is also called as sub-ordinate grass. Mainly sub-ordinate grass is taken from the outside as naturally and the grass is relived to the atmosphere and the grass is totally changed to dry condition the grass is subjected to heat at the temperature nearly $50^{\circ}$ c.mainly the grass is heated to atmospheric to convert the silica into silicone.

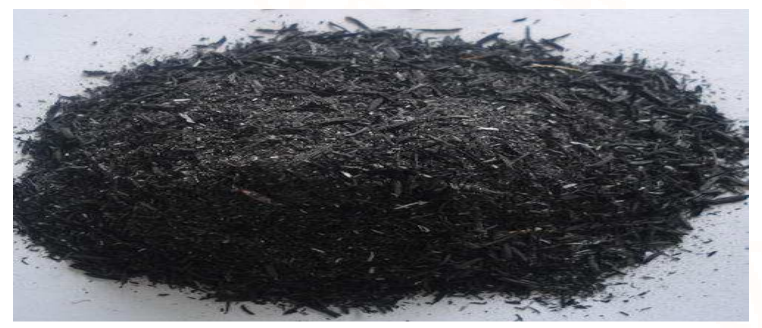

Figure 4 Subordinate grass ash

\section{Preparation of Binder:-}

The polyvinyl alchoal is used as a binder in this fabricaton the binder is in a powder form and this binder is used in liquid form as the binder is taken in 5 grams by weight in according to standards. the binder 
is taken in a $100 \mathrm{ml}$ beaker and the beaker is placed on a magneto stirrer with hot plate at temperature of $60^{\circ} \mathrm{c}$ at a speed of $60 \mathrm{rpm}$ of 1 hour of time. The binder is prepared.

\section{Fabrication of Ceramic SOL-GEL method:}

Sol-gel process is based on the possibility of forming the disordered network of ceramics not directly at high temperatures from the melt but at low temperatures from suitable compounds by the chemical polymerization in liquid phase. When the viscosity of a sol increases sufficiently, usually through the partial loss of its liquid phase, its become rigid. The rigid material is termed as gel. However in the field of ceramics and glass, the term of sol gel has come to have a broder meaning. This process, though initially used for making pure oxide glasses and ceramics is presently being investigated for making oxycarbides, carbides. Solgel process involves preparation of soln, aging of soln at suitable temperature, casting, drying followed by heating to obtain desirable product.

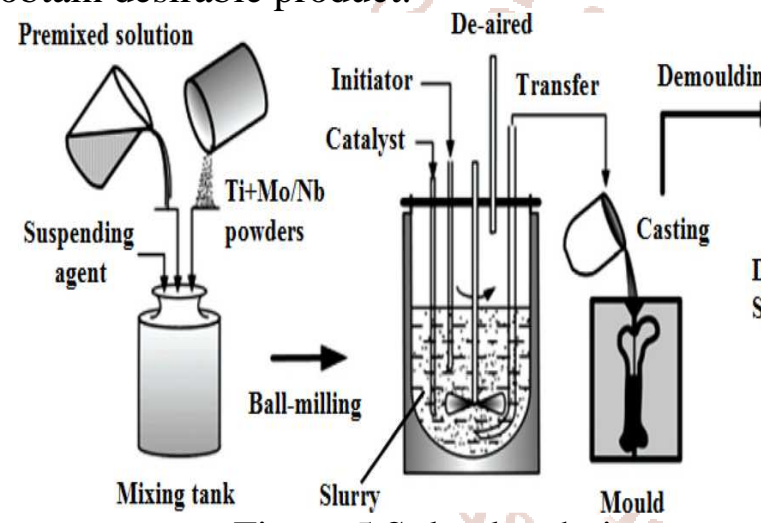

Figure 5 Sol gel technique
Fabrication steps

Step 1: The fabrication of ceramics firstly the compositioin is mixed acoording to the propostions.

Step 2: The composition is mixed with binder.

Step 3: The slurry compound is taken in a moulds of rectangular and circular in shape.

Step 4: The dies are pressed under the fly press to remove water content in slurry compound.

Step 5: The prepared rectangular and circular green pieces are placed under atmospheric temperature for a day.

Step 6: The dried green pieces are placed in the furnace of 1000deg c for 3 hours.

Step 7: The prepared samples are taken from furnace and used for flexural and compression stress.

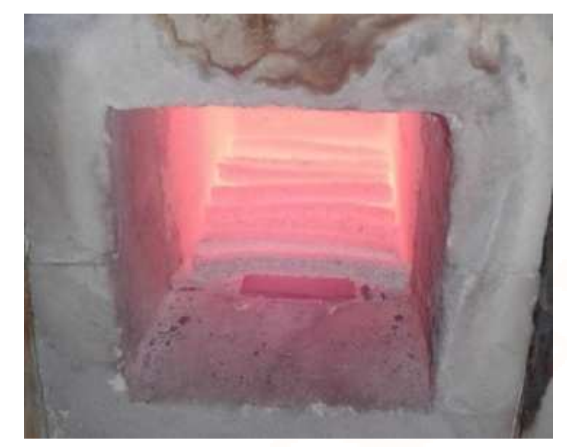

Figure 6 Ceramic samples placed in furnace

\section{CHARACTERIZATIONOF MECHANICAL PROPERTIES:}

\section{COMPRESSION TEST:}

Compression test generally perform on cylindrical specimens. This test of ceramic samples is carried out by using cylindrical samples. In this test a uniaxial load was applied through the both ends of the specimen and this test is carried out by using universal testing machine.

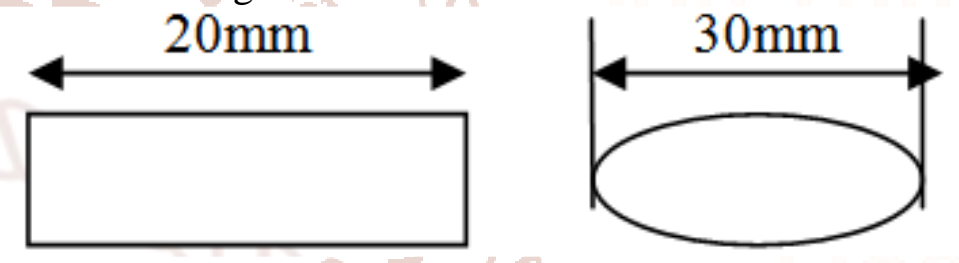

\section{FLEXURAL TEST:}

Flexural test is to determine the capability of material to withstand bending force before reaching breaking point. This test is done on a three point bending system. Samples are tested in a universal testing machine.
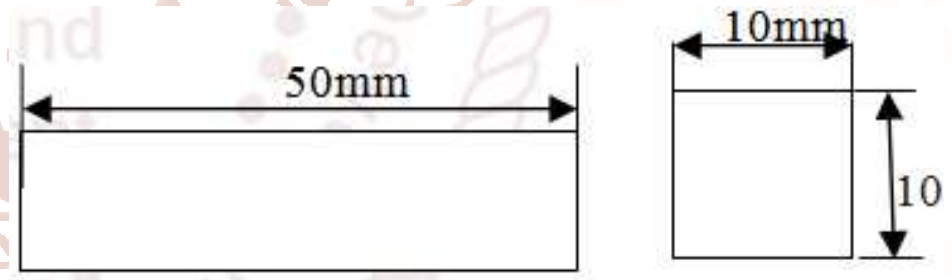

TESTING AND RESULTS:

\section{COMPRESSION TEST:}

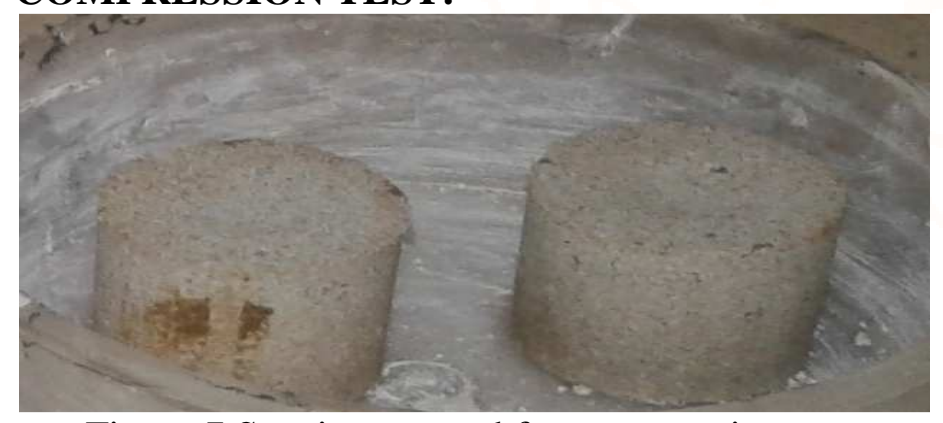

Figure 7 Specimens used for compression test 
International Journal of Trend in Scientific Research and Development (IJTSRD) ISSN: 2456-6470

Table1. Compression Test Result

\begin{tabular}{|c|c|c|c|}
\hline S. No & Samples & Load(N) & $\begin{array}{c}\text { Strength } \\
(\mathbf{N} / \mathbf{M} \text { 2) }\end{array}$ \\
\hline 1 & S65 & 89019.5 & 94.5 \\
\hline 2 & S70 & 85062.6 & 90.3 \\
\hline 3 & S80 & 84309.3 & 89.5 \\
\hline
\end{tabular}

\section{Formula:}

Compression strength $=$ compressive load $/$ cross section area

\section{FLEXURAL TEST:}

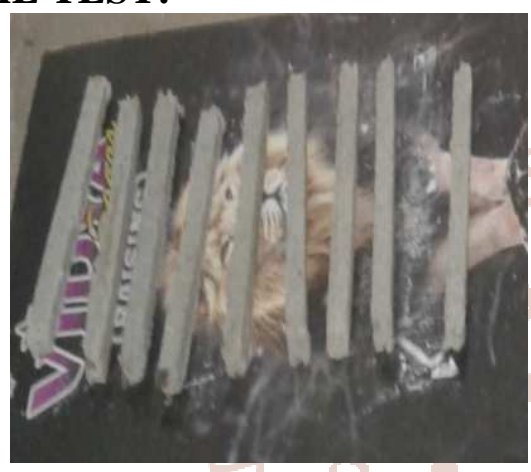

Figure 8 Samples used for flexural test

Table2. Flexural Test Results

\begin{tabular}{|c|c|c|c|}
\hline S. No & Specimen Type & Load (N) & $\begin{array}{c}\text { Strength } \\
(\mathbf{N} / \mathbf{M m} \text { 2) }\end{array}$ \\
\hline 1 & S65 & 368 & 55.2 \\
\hline 2 & S70 & 331.3 & 49.6 \\
\hline 3 & S80 & 327.6 & 49.14 \\
\hline
\end{tabular}

Flexural strength $\sigma=\frac{3 \mathrm{FL}}{2 \square \square^{2}}$

Where

$\mathrm{F}$ is the maximum load

$\mathrm{L}$ is length of support span

$B$ is the width of the specimen

$\mathrm{D}$ is the thickness of the specimen.

\section{DISCUSSIONS:}

The samples that are taken according to the composition and the samples are prepared by varying the composition of silica as S65, S70, S80.

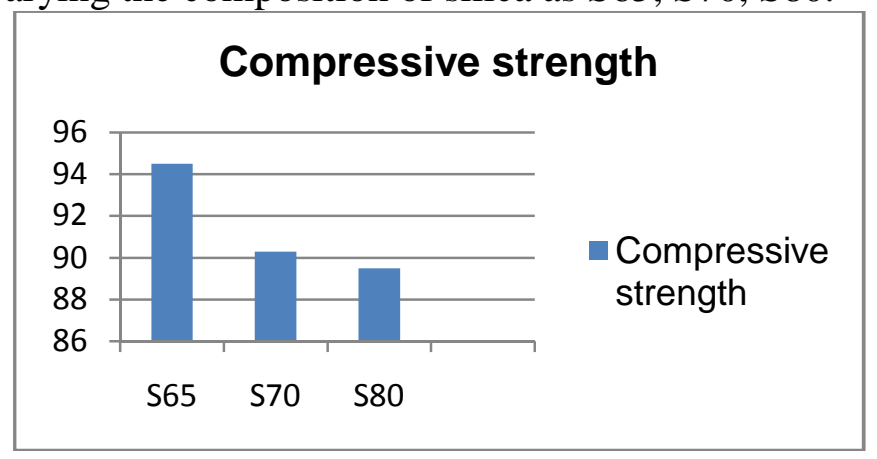

Figure 9 Compressive strength vs silica percentage
The comparison of silica percentage and flexural strength is drawn in a bar chart. The value is taken according to the percentages.

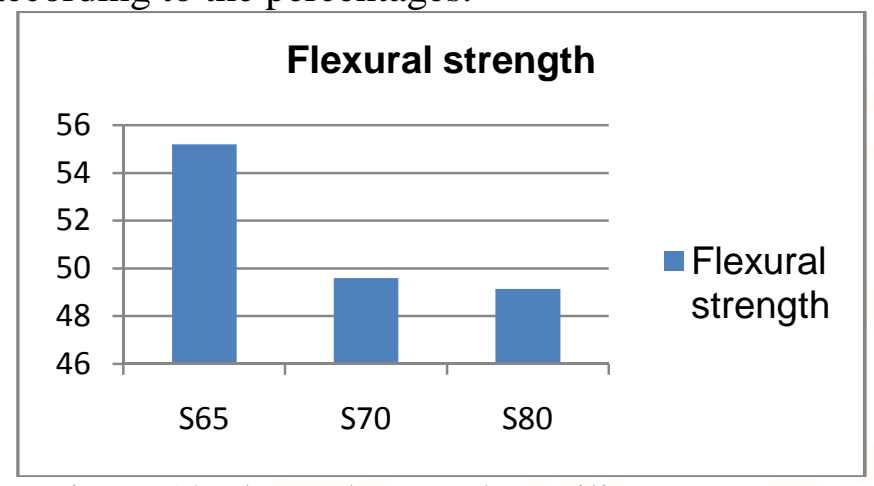

Figure 10 Flexural strength vs silica percentage

\section{CONCLUSION}

The experimental study on the effect on mechanical properties of ceramics by using sub-ordinate grass ash as a source of silica as the mechanical properties as compression, flexural, water absorption and porosity lead to the following conclusions:

1. The successful fabrication of a new bio material ceramics with sub-ordinate grass ash as source of silica have been done by using sol-gel technique.

2. Sub-ordinate grass ash is used as a source of silica and by changing the composition of silica the properties are evolved.

3. The mechanical properties that are compression, flexural is successfully evolved.

Ceramics that have maximum compression strength that can be having silica content has minimum. By increasing the silica content in the ceramics that can result in the decreasing of strength. That the ceramics are exhibiting maximum compressive strength as subordinate grass ash is used as source of silica.

Ceramics that are exhibiting maximum flexural strength of having moderate silica content. By increasing the silica content may result in the decreasing of strength minutely, by the researches it can be clarifying that the ceramics are having minimum flexural strength than compressive strength. Ceramics are exhibiting maximum flexural strength as subordinate grass ash is used as a source of silica.

\section{REFERENCES}

1. K. Okada. "Activation energy of mullitization from various starting materials." J. Eur. Ceram. Soc., vol. 28, pp. 377-382, 2008.

2. R. Svinka, V. Svinka, G. Bula, T. Juettner, E. Palcevskis. "Influence of suspensions theology on 
the properties of light weight high temperature materials." Adv. Sci. Technol., vol. 45, pp. 22662271, 2006.

3. T. Juettner, H. Moertel, V. Svinka, R. Svinka. "Structure of kaoline - alumina based foam ceramics for high temperature applications." J. Eur. Ceram. Soc., vol. 27, pp. 1435-1441, 2007.

4. H. J. Kleebe, F. Siegelin, T. Straubinger, G. Ziegler. "Conversion of $\mathrm{Al} 2 \mathrm{O} 3-\mathrm{SiO} 2$ powder mixtures to $3: 2$ mullite following the stable or meta stable phase diagram." J. Eur. Ceram. Soc., vol. 21, pp. 2521-2533\, 2001.

5. A. Aras. "The change of phase composition in kaolinite- and illite-rich clay-based ceramic bodies." Appl. Clay Sci., vol. 24, pp. 257-269, 2004.

6. H. Schneider, S. Komarneni. "Mullite." WILEYVCH Verlag GmbH \& Co.KGaA, pp. 180-190, 2005.

7. Encyclopedia Britannica Online, s. v. "aluminosilicate: phase diagram of the aluminasilica system", accessed October 27, 2011.

8. H. Schneider, E. Eberhard. "Thermal expansion of mullite”. J. Am. Ceram. Soc., vol. 73, pp. 20732076, 1990.

9. B. Nait-Ali, K. Haberko, H. Vesteghem, J. Absi, D. S. Smith. "Preparation and thermal conductivity characterisation of highly porous ceramics: Comparison between experimental results, analytical calculations and numerical simulations." J. Am. Ceram. Soc., vol. 27, pp. 1345-1350, 2007.

10. A. Esharghawi, C. Penot, F. Nardou. "Contribution to porous mullite synthesis from clays by adding $\mathrm{Al}$ and Mg powders." J. Eur. Ceram. Soc., vol. 29, pp. 31-38, 2009.

11. Cornejo, I. A., Rama lingam, S., Fish, J. S. \& Reimanis, I. E. Hidden treasures: Turning food waste into glass. Am. Ceram. Soc. Bull. 93, 24-27 (2014).

12. Bondioli, F., Barbieri, L., Ferrari, A. M. \& Manfredini, T. Characterization of Rice Husk Ash and Its Recycling as Quartz Substitute for the Production of Ceramic Glazes. J. Am. Ceram. Soc. 93, 121-126 (2010).
13. Yalçin, N. \& Sevinç, V. Studies on silica obtained from rice husk. Ceram. Int. 27, 219-224 (2001).

14. Nayak, J. P. \& Bera, J. A Simple Method for Production of Humidity Indicating Silica Gel from Rice Husk Ash. J. Met. Mater. Miner. 19, 15-19 (2009).

15. Singh, N. B., Das, S. S., Singh, N. P. \& Dwivedi, V. N. Studies on SCLA composite Portland cement. Indian J. Eng. Mater. Sci. 16, 415-422 (2009).

16. Chandrasekhar, S., Satyanarayana, K. G., Pramada, P. N., Raghavan, P. \& Gupta, T. N. Processing, properties and applications of reactive silica from rice husk - an overview. J. Mater. Sci. 38, 3159-3168 (2003).

17. Zhao, P., Guo, X. \& Zheng, C. Removal of elemental mercury by iodine-modified rice husk ash sorbents. J. Environ. Sci. 22, 1629-1636 (2010).

18. Nayak, J. P. \& Bera, J. Effect of sintering temperature on mechanical behaviour and bioactivity of sol-gel synthesized bioglassceramics using rice husk ash as a silica source. Appl. Surf. Sci. 257, 458-462 (2010).

19. Amick, J. A. Purification of Rice Hulls as a Source of Solar Grade Silicon for Solar Cells Purification of Rice Hulls as a Source of Solar Grade Silicon for Solar Cells. J. Electrochem. Soc. 129, 864-866 (1982).

20. Chen, B., Wang, K., Chen, X. \& Lu, A. Study of Foam Glass with High Content of Fly Ash Using Calcium Carbonate as Foaming Agent. Mater. Lett. 79, 263-265 (2012).

21. Wersing, W. Microwave ceramics for resonators and filters. Curr. Opin. Solid State Mater. Sci. 1, 715-731 (1996).

22. Bauer, T. Thermo photovoltaic's: Basic Principles and Critical Aspects of System Design. (Springer, Berlin Heidelberg, 2011).

23. Shelby, J. E. Introduction to Glass Science and Technology. (Royal Society of Chemistry, Cambridge, 2005).

24. Friebele, E. J., Griscom, D. L. \& Stapelbroek, M. Fundamental defect centers in glass: The peroxy radical in irradiated, high-purity, fused silica. Phys. Rev. Lett. 42, 1346-1349 (1979). 